\title{
Two-Dimensional Wide-Band-Gap II-V Semiconductors with a Dilated Graphene-like Structure
}

\author{
Xue-Jing Zhang ${ }^{1,2}$ and Bang-Gui Liu ${ }^{1,2, \text { : }}$ \\ ${ }^{1}$ Beijing National Laboratory for Condensed Matter Physics, \\ Institute of Physics, Chinese Academy of Sciences, Beijing 100190, China \\ ${ }^{2}$ School of Physical Sciences, University of Chinese Academy of Sciences, Beijing 100190, China
}

(Dated: July 7, 2016)

\begin{abstract}
Since the advent of graphene, two-dimensional (2D) materials become very attractive and there is growing interest to explore new 2D beyond graphene. Here, through density functional theory (DFT) calculations, we predict $2 \mathrm{D}$ wide-band-gap II-V semiconductor materials of $\mathrm{M}_{3} \mathrm{X}_{2}(\mathrm{M}=\mathrm{Zn}$, $\mathrm{Cd}$ and $\mathrm{X}=\mathrm{N}, \mathrm{P}, \mathrm{As}$ ) with a dilated graphene-like honeycomb structure. The structure features that the group- $\mathrm{V} \mathrm{X}$ atoms form two $\mathrm{X}$-atomic planes symmetrically astride the centering group-IIB M atomic plane. The $2 \mathrm{D} \mathrm{Zn}_{3} \mathrm{~N}_{2}, \mathrm{Zn}_{3} \mathrm{P}_{2}$, and $\mathrm{Zn}_{3} \mathrm{As}_{2}$ are shown to have direct band gaps of 2.87, 3.81, and $3.55 \mathrm{eV}$, respectively, and the $2 \mathrm{D} \mathrm{Cd}_{3} \mathrm{~N}_{2}, \mathrm{Cd}_{3} \mathrm{P}_{2}$, and $\mathrm{Cd}_{3} \mathrm{As}_{2}$ exhibit indirect band gaps of $2.74,3.51$, and $3.29 \mathrm{eV}$, respectively. Each of the six 2D materials is shown to have effective carrier (either hole or electron) masses down to $0.03 \sim 0.05 \mathrm{~m}_{0}$. The structural stability and feasibility of experimental realization of these $2 \mathrm{D}$ materials has been shown in terms of DFT phonon spectra and total energy comparison with related existing bulk materials. On the experimental side, there already are many similar two-coordinate structures of $\mathrm{Zn}$ and other transition metals in various organic materials, which can be considered to support our DFT prediction. Therefore, these 2D semiconductors can enrich the family of $2 \mathrm{D}$ electronic materials and may have promising potential for achieving novel transistors and optoelectronic devices.

PACS numbers: 68.65.-k, 73.22.-f, 78.67.-n
\end{abstract}

\section{INTRODUCTION}

Since graphene was created, two-dimensional (2D) materials have been attracting a lot of attention due to their unique and exceptionally important properties and promising applications in next-generation electronic, optoelectronic, spintronic, and other novel devices $\underline{\underline{1}}-\underline{\underline{-}}$. Graphene, with massless Dirac Fermions weakly sensitive to backscattering and travelling at very high speed over very wide distances at room temperature $e^{\underline{6}}$, has superior performance, but its zero-gap behavior is an obstacle to switch current on and off in field-effect transistors (FETs), being inconsistent with modern semiconductor technology $y^{3,4,8,9}$. As for other $2 \mathrm{D}$ compounds, h-BN has a wide gap of $5.5 \mathrm{eV}^{10}$ and on the other hand, $\mathrm{MoS}_{2}$ monolayer, black phosphorene, and As monolayer have band gaps of 1.8, 1.51, and $2.49 \mathrm{eV}^{11} \underline{13}$, respectively. Monolayer $\mathrm{MoS}_{2}$ FET have been demonstrated with carrier mobility of $200 \mathrm{~cm}^{2} \mathrm{~V}^{-1} \mathrm{~s}^{-1}$ at room temperature, current on/off ratios of $1 \times 10^{8}$, and ultralow standby power dissipation 14 . Black $\mathrm{P}$, arranged in a honeycomb puckered lattice, presents a high electron mobility of 1000 $\mathrm{cm}^{2} \mathrm{~V}^{-1} \mathrm{~s}^{-1}$ and high in-plane anisotropy ${ }^{15,16}$. These 2D materials can be applied in nanoelectronic devices. However, the $2 \mathrm{D}$ semiconductors with band gaps of $2.5 \sim 5.0$ $\mathrm{eV}$ are highly desirable for rich applications in electronic and optoelectronic devices.

Here, we predict six 2D II-V wide-band-gap semiconductors $\mathrm{M}_{3} \mathrm{X}_{2}(\mathrm{M}=\mathrm{Zn}, \mathrm{Cd}$ and $\mathrm{X}=\mathrm{N}, \mathrm{P}, \mathrm{As})$ through systematical density functional theory (DFT) calculations. The dilated graphene-like honeycomb structures of the $2 \mathrm{D} \mathrm{M}_{3} \mathrm{X}_{2}(\mathrm{M}=\mathrm{Zn}, \mathrm{Cd}$ and $\mathrm{X}=\mathrm{N}, \mathrm{P}, \mathrm{As})$ are formed ac- cording to normal valence rules that each group-IIB $M$ atom is surrounded by two group- $\mathrm{V} \mathrm{X}$ atoms and each $\mathrm{X}$ is surrounded by three $\mathrm{M}$ atoms. The structural stability and feasibility of experimental realization of these $2 \mathrm{D}$ materials has been investigated in terms of DFT structural optimization, phonon spectra, and total energy comparison with related existing $3 \mathrm{D}$ materials. On the experimental side, similar two-coordinate structures of metallic atoms have been observed in various organic materials 17,18 . Our DFT study shows that these 2D semiconductors have wide band gaps ranging from 2.74 to $3.81 \mathrm{eV}$ and most of their effective carrier masses are from 0.03 to $0.05 m_{0}$. They may be potential materials for achieving novel transistors with high on/off ratios and optoelectronic devices working under violet or UV light. More detailed results will be presented in the following.

\section{COMPUTATIONAL DETAILS}

Our first-principles calculations are performed with the projector-augmented wave method as implemented in the Vienna Ab-initio Simulation Package (VASP) ${ }^{19,20}$. The valence-electron configuration of group-IIB $\mathrm{M}$ and group$\mathrm{V} \mathrm{X}$ are $\mathrm{d}^{10} \mathrm{~s}^{2}$ and $\mathrm{s}^{2} \mathrm{p}^{3}$, respectively. We use a slab model to simulate the $2 \mathrm{D}$ materials by adding a $15 \AA$ thick vacuum layer to ensure the decoupling between different trilayers (consisting of one $\mathrm{M}$ layer and two $\mathrm{X}$ layers) in the calculational model. A $\Gamma$-centered $9 \times 9 \times 1 \mathrm{k}$-grid is employed and the plane wave energy cutoff is set to $500 \mathrm{eV}$. Furthermore, the convergence criterium for the total energy is chosen to be $10^{-5} \mathrm{eV}$. The cell geometry and the 

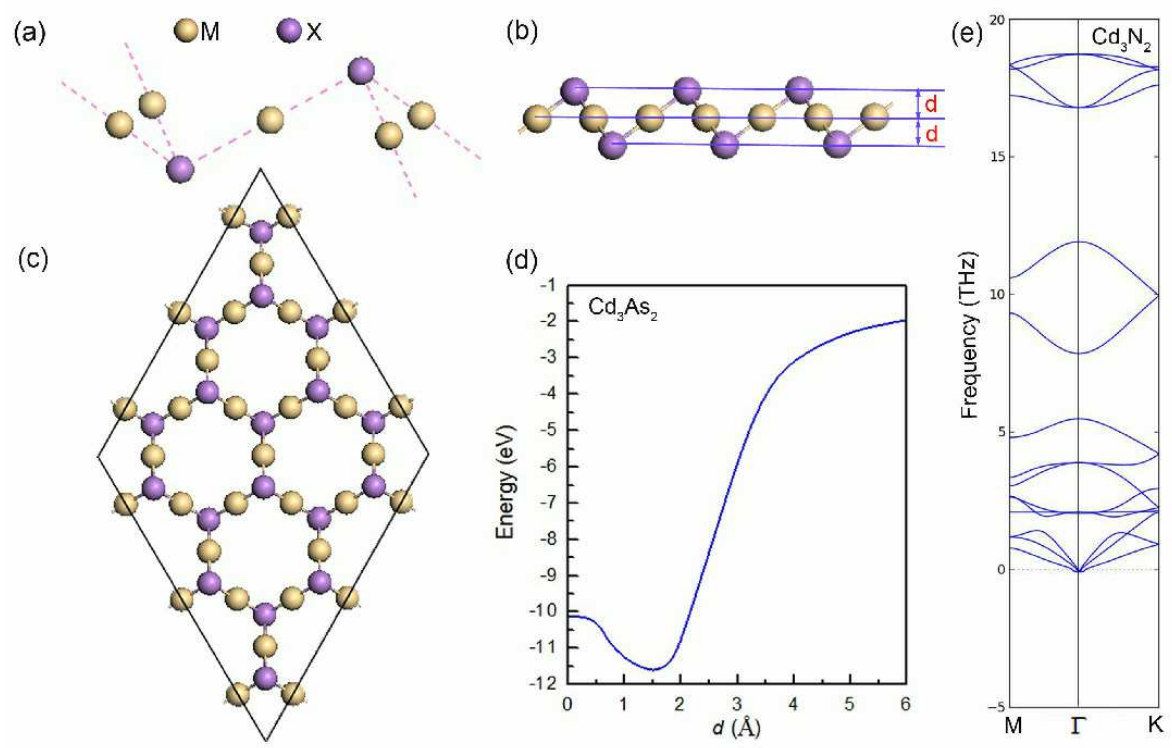

FIG. 1. (Color online) (a) Crystal structure of the $2 \mathrm{D}$ II-V materials of $\mathrm{M}_{3} \mathrm{X}_{2}(\mathrm{M}=\mathrm{Zn}, \mathrm{Cd}$ and $\mathrm{X}=\mathrm{N}, \mathrm{P}, \mathrm{As})$. (b, c) Side and top views of the buckled $2 \mathrm{D} \mathrm{M}_{3} \mathrm{X}_{2}(\mathrm{M}=\mathrm{Zn}, \mathrm{Cd}$ and $\mathrm{X}=\mathrm{N}, \mathrm{P}, \mathrm{As})$. (d) The energy of the $2 \mathrm{D} \mathrm{Cd}_{3} \mathrm{As}_{2}$ with the largest buckling as a function of buckling parameter $d$. (e) Phonon spectra of the $2 \mathrm{D} \mathrm{Cd}_{3} \mathrm{~N}_{2}$ as the representative.

ionic positions are both optimized until the HellmannFeynmann forces on each atom become less than 0.01 $\mathrm{eV} / \AA$. For structure optimization, we use the generalized gradient approximation (GGA) by Perdew, Burke and Ernzerhof $(\mathrm{PBE})^{21}$ for the exchange-correlation potential. The electronic structures (DOSs and bands) are calculated by both PBE and hybrid functional HSE06. ${ }^{22}$ The latter is used to improve the theoretical description of the electronic structures, especially the semiconductor gaps. Phonon spectra are calculated based on Phonopy 23,24 .

\section{RESULTS AND DISCUSSION}

\section{A. Structures and stability}

For constructing reasonable $2 \mathrm{D}$ structures for $\mathrm{M}_{3} \mathrm{X}_{2}$ $(\mathrm{M}=\mathrm{Zn}, \mathrm{Cd}$ and $\mathrm{X}=\mathrm{N}, \mathrm{P}, \mathrm{As})$, the valences of group-IIB $\mathrm{M}$ and group- $\mathrm{V} \mathrm{X}$ must be taken into account. First, we can assume that $\mathrm{M}$ and $\mathrm{X}$ are in the same plane and form a $2 \mathrm{D}$ dilated-honeycomb structure (space group $\mathrm{P} 6 / \mathrm{mmm}$ ), in which each $\mathrm{M}$ has two $\mathrm{X}$ neighbors and each $\mathrm{X}$ has three $\mathrm{M}$ ones. This structure has the same rotational symmetry as grapheme, but the $\mathrm{C}$ atom at the hexagonal vertex is replaced by $\mathrm{X}$ atom and there is an $\mathrm{M}$ atom at the middle of each dilated hexagonal edge of the honeycomb unit. There are six $\mathrm{M}$ and six $\mathrm{X}$ atoms in the hexagon of the honeycomb unit. Unfortunately, this structure is unstable against a buckling of $\mathrm{X}$ atoms from the plane. The buckling, keeping the three-fold rotational symmetry, makes two X planes remain symmetrically astride the $\mathrm{M}$ plane and it can be parameterized with the distance $d$ between the M plane and both of the two X planes. This buckling makes the space group reduce to $\mathrm{P} \overline{3} \mathrm{~m} 1$, but lowers the total energy by $0.042,1.027,1.419,0.215,1.076$, and $1.476 \mathrm{eV}$ per formula unit for the $\mathrm{Zn}_{3} \mathrm{~N}_{2}, \mathrm{Zn}_{3} \mathrm{P}_{2}, \mathrm{Zn}_{3} \mathrm{As}_{2}, \mathrm{Cd}_{3} \mathrm{~N}_{2}, \mathrm{Cd}_{3} \mathrm{P}_{2}$, and $\mathrm{Cd}_{3} \mathrm{As}_{2}$, respectively. With the optimized $d$ value and the 2D crystal lattice constant $a$, we can calculate the M-X bond length $l_{\mathrm{MX}}$. We summarize $a, d$, and $l_{\mathrm{MX}}$ values in Table I, and present the $2 \mathrm{D}$ crystal structure in Figs. 1(a)-(c). It is clear that this 2D structure can be seen as a dilated, buckled honeycomb structure like graphene. To better demonstrate the effect of the buckling, we present the total energy of the $2 \mathrm{D} \mathrm{Cd}_{3} \mathrm{As}_{2}$ as a function of $d$ in Fig. 1(d) because of the largest buckling in this case. Furthermore, we have calculated the phonon spectra in all the six cases. The phonon spectra of the $2 \mathrm{D}$ $\mathrm{Cd}_{3} \mathrm{~N}_{2}$ as the representative are presented in Fig. 1(e). Because there is no soft phonon mode, there is no kinetic instability for any of the six $2 \mathrm{D} \mathrm{M}_{3} \mathrm{X}_{2}(\mathrm{M}=\mathrm{Zn}, \mathrm{Cd}$ and $\mathrm{X}=\mathrm{N}, \mathrm{P}, \mathrm{As}$ ) materials ${ }^{25}$.

For analyzing the energy stability of the $2 \mathrm{D} \mathrm{M}_{3} \mathrm{X}_{2}$ $(\mathrm{M}=\mathrm{Zn}, \mathrm{Cd}$ and $\mathrm{X}=\mathrm{N}, \mathrm{P}, \mathrm{As})$ and their feasibility of being experimentally synthesized, we need to compare their total energies with those of corresponding 3D bulk materials that have already been experimentally realized, in addition to checking the phonon spectra. These 3D bulk materials assume different crystal structures with space groups: Ia $\overline{3}$ (for $\mathrm{Zn}_{3} \mathrm{~N}_{2}$ and $\mathrm{Cd}_{3} \mathrm{~N}_{2}$ ) ${ }^{26-28}, \mathrm{P}_{2} / \mathrm{nmc}$ (for $\mathrm{Zn}_{3} \mathrm{P}_{2}, \mathrm{Cd}_{3} \mathrm{P}_{2}, \mathrm{Zn}_{3} \mathrm{As}_{2}$ and $\left.\mathrm{Cd}_{3} \mathrm{As}_{2}\right)^{29} \underline{\underline{34}}$, and $\mathrm{P}_{2} 32$ (for $\mathrm{Zn}_{3} \mathrm{P}_{2}, \mathrm{Cd}_{3} \mathrm{P}_{2}, \mathrm{Zn}_{3} \mathrm{As}_{2}$ and $\left.\mathrm{Cd}_{3} \mathrm{As}_{2}\right)^{35}$. We have calculated the energy differences per atom, $\Delta E$, between the $2 \mathrm{D} \mathrm{M}_{3} \mathrm{X}_{2}(\mathrm{M}=\mathrm{Zn}, \mathrm{Cd}$ and $\mathrm{X}=\mathrm{N}, \mathrm{P}, \mathrm{As})$ and the corresponding $3 \mathrm{D}$ crystal materials, and present the calcu- 
TABLE I. Calculated 2D lattice constant $a$, buckling parameter $d$, and M-X bond length $l_{\mathrm{MX}}$ of the $2 \mathrm{D}$ II-V materials of $\mathrm{M}_{3} \mathrm{X}_{2}(\mathrm{M}=\mathrm{Zn}, \mathrm{Cd}$ and $\mathrm{X}=\mathrm{N}, \mathrm{P}, \mathrm{As})$. Also presented are calculated energy difference values per atom, $\Delta E$, between the $2 \mathrm{D} \mathrm{M}_{3} \mathrm{X}_{2}$ materials and the $3 \mathrm{D}$ bulk $\mathrm{M}_{3} \mathrm{X}_{2}$ with space group Ia $\overline{3}$ (for bulk $\mathrm{Zn}_{3} \mathrm{~N}_{2}$ and $\left.\mathrm{Cd}_{3} \mathrm{~N}_{2}\right)^{26-28}$ and space groups $\mathrm{P} 4_{2} / \mathrm{nmc}$ and $\mathrm{P} 4_{2} 32$ (for bulk $\mathrm{M}_{3} \mathrm{X}_{2}$ with $\mathrm{M}=\mathrm{Zn}, \mathrm{Cd}$ and $\mathrm{X}=\mathrm{P}, \mathrm{As})^{29-35}$

\begin{tabular}{lllcc}
\hline \hline System & $a(\AA)$ & $d(\AA)$ & $l_{\mathrm{Mx}}(\AA)$ & $\Delta E(\mathrm{eV})$ \\
\hline $\mathrm{Zn}_{3} \mathrm{~N}_{2}$ & 6.157 & 0.427 & 1.828 & 0.207 \\
$\mathrm{Zn}_{3} \mathrm{P}_{2}$ & 6.418 & 1.291 & 2.258 & $0.259,0.075$ \\
$\mathrm{Zn}_{3} \mathrm{As}_{2}$ & 6.484 & 1.453 & 2.370 & $0.211,0.054$ \\
$\mathrm{Cd}_{3} \mathrm{~N}_{2}$ & 6.745 & 0.628 & 2.063 & 0.207 \\
$\mathrm{Cd}_{3} \mathrm{P}_{2}$ & 7.121 & 1.344 & 2.456 & $0.219,0.029$ \\
$\mathrm{Cd}_{3} \mathrm{As}_{2}$ & 7.185 & 1.505 & 2.563 & $0.185,0.032$ \\
\hline \hline
\end{tabular}

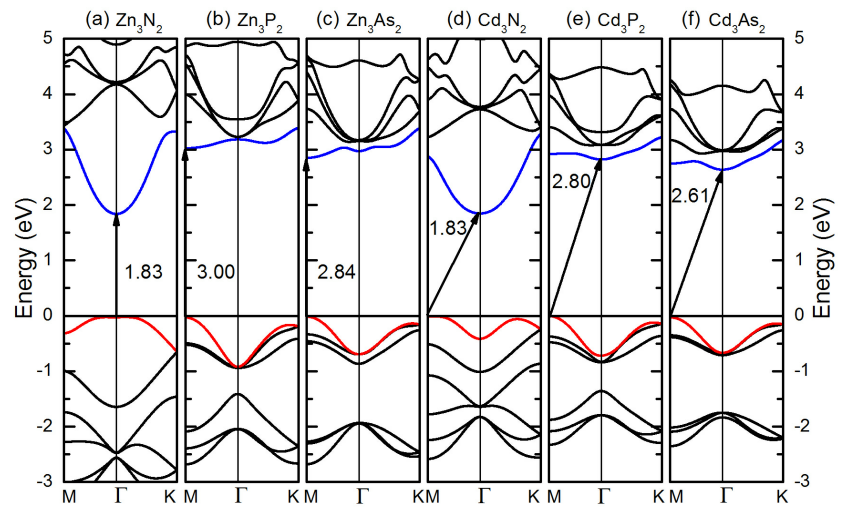

FIG. 2. (Color online) The band structures $\left(E_{F}=0 \mathrm{eV}\right)$ calculated with $\mathrm{PBE}^{21}$ for the six $2 \mathrm{D}$ semiconductors of $\mathrm{M}_{3} \mathrm{X}_{2}$ $(\mathrm{M}=\mathrm{Zn}, \mathrm{Cd}$ and $\mathrm{X}=\mathrm{N}, \mathrm{P}, \mathrm{As})$.

lated results in Table I. As for both $\mathrm{Zn}_{3} \mathrm{~N}_{2}$ and $\mathrm{Cd}_{3} \mathrm{~N}_{2}$, the $\Delta E$ value is an energy difference per atom of $0.21 \mathrm{eV}$. For both $\mathrm{Cd}_{3} \mathrm{P}_{2}$ and $\mathrm{Cd}_{3} \mathrm{As}_{2}$, the energy difference per atom is $0.03 \mathrm{eV}$, the smallest. The largest value for the energy difference per atom is 0.26 in the case of $\mathrm{Zn}_{3} \mathrm{P}_{2}$. Therefore, these small energy differences, ranging from $0.03 \mathrm{eV}$ to $0.26 \mathrm{eV}$, with the phonon spectra free of any soft mode, imply that these 2D materials could be realized experimentally.

\section{B. Electronic structures}

We present in Fig. 2 the electronic band structures of the $2 \mathrm{D} \mathrm{M}_{3} \mathrm{X}_{2}(\mathrm{M}=\mathrm{Zn}, \mathrm{Cd}$ and $\mathrm{X}=\mathrm{N}, \mathrm{P}, \mathrm{As})$ calculated with PBE. It is clear that the $\mathrm{Zn}_{3} \mathrm{~N}_{2}$ is a direct band gap semiconductor with a band gap of $1.83 \mathrm{eV}$ at $\Gamma$ point of the Brillouin zone, while the $\mathrm{Zn}_{3} \mathrm{P}_{2}$ and the $\mathrm{Zn}_{3} \mathrm{As}_{2}$ are direct band gap semiconductors with band gaps of 3.00 and $2.84 \mathrm{eV}$ at $\mathrm{M}$ point. However, the $2 \mathrm{D} \mathrm{Cd}_{3} \mathrm{X}_{2}$ $(\mathrm{X}=\mathrm{N}, \mathrm{P}, \mathrm{As})$ are indirect band gap semiconductors with band gaps of $1.83,2.80$ and $2.61 \mathrm{eV}$, and their valence band maxima (VBM) are at $\mathrm{M}$ point and their conduc-

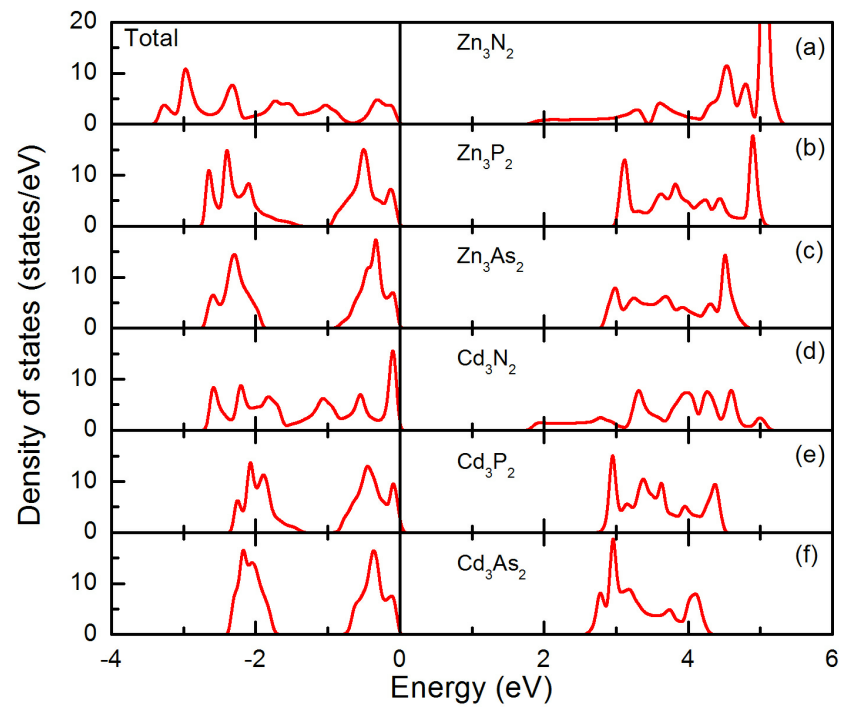

FIG. 3. (Color online) The total DOS $\left(E_{F}=0 \mathrm{eV}\right)$ calculated with $\mathrm{PBE}^{21}$ of the six $2 \mathrm{D}$ II-V materials of $\mathrm{M}_{3} \mathrm{X}_{2}(\mathrm{M}=\mathrm{Zn}, \mathrm{Cd}$ and $\mathrm{X}=\mathrm{N}, \mathrm{P}, \mathrm{As})$.

tion band minima $(\mathrm{CBM})$ at $\Gamma$ point. The total DOSs of the $2 \mathrm{D} \mathrm{M}_{3} \mathrm{X}_{2}(\mathrm{M}=\mathrm{Zn}, \mathrm{Cd}$ and $\mathrm{X}=\mathrm{N}, \mathrm{P}, \mathrm{As})$ are presented in Fig. 3. The energy distribution of total DOS varies with different anion $X(X=N, P, A s)$. The band gap of the $\mathrm{Zn}_{3} \mathrm{X}_{2}(\mathrm{X}=\mathrm{N}, \mathrm{P}$, or As $)$ is slightly larger than that of the corresponding $\mathrm{Cd}_{3} \mathrm{X}_{2}$, respectively.

Fig. 4 shows the partial DOSs of $\mathrm{N}$ and $\mathrm{Zn}$ in the $2 \mathrm{D}$ $\mathrm{Zn}_{3} \mathrm{~N}_{2}$, those of $\mathrm{N}$ and $\mathrm{Cd}$ in the $2 \mathrm{D} \mathrm{Cd}_{3} \mathrm{~N}_{2}$, and those of $\mathrm{As}$ and $\mathrm{Cd}$ in the $2 \mathrm{D} \mathrm{Cd}_{3} \mathrm{As}_{2}$. It can be seen that the VBM of these $\mathrm{M}_{3} \mathrm{X}_{2}$ materials arise from the X p orbitals. For the $2 \mathrm{D} \mathrm{Zn}_{3} \mathrm{~N}_{2}, \mathrm{~N} \mathrm{p}_{z}$ state dominates between $-1.7 \mathrm{eV}$ and $0 \mathrm{eV}$ and the $\mathrm{p}_{x}$ and $\mathrm{p}_{y}$ states hybrid with $\mathrm{Zn} \mathrm{d}$ and $\mathrm{s}$ states in the window from $-3.42 \mathrm{eV}$ to $-1.38 \mathrm{eV}$. The $\mathrm{N}-\mathrm{p}$ dominant bands in the $\mathrm{Cd}_{3} \mathrm{~N}_{2}$ are more narrow than those in the $\mathrm{Zn}_{3} \mathrm{~N}_{2}$. Near the VBM (from $-0.25 \mathrm{eV}$ to 0 $\mathrm{eV}$ ) of the $2 \mathrm{D} \mathrm{Cd}_{3} \mathrm{~N}_{2}$, there is a strong peak of the $\mathrm{p}_{z}$ state with small $\mathrm{p}_{x}$ and $\mathrm{p}_{y}$ states admixtures. The $\mathrm{N}_{x}$ and $\mathrm{p}_{y}$ states hybrid with $\mathrm{Cd} \mathrm{s}$ and $\mathrm{d}$, as demonstrated in the energy window from $-2.7 \mathrm{eV}$ to $-1.6 \mathrm{eV}$. In the $2 \mathrm{D} \mathrm{Cd}_{3} \mathrm{As}_{2}$, As p states dominate between -0.8 and $0 \mathrm{eV}$ and hybrid with $\mathrm{Cd}$ s states $(\mathrm{Cd} d$ states are too small to need to be shown here) between -2.3 and $-1.7 \mathrm{eV}$. Our calculations also show that the partial DOSs of the 2D $\mathrm{Zn}_{3} \mathrm{P}_{2}, \mathrm{Cd}_{3} \mathrm{P}_{2}$, and $\mathrm{Zn}_{3} \mathrm{As}_{2}$ are similar to those of the $2 \mathrm{D}$ $\mathrm{Cd}_{3} \mathrm{As}_{2}$.

\section{Improved electronic properties}

It is well known that GGA usually underestimates semiconductor gaps. We use HSE06 functional ${ }^{22}$ to achieve a better description of band gaps in the $2 \mathrm{D}$ semiconductors. The electronic band structures of the six $2 \mathrm{D} \mathrm{M}_{3} \mathrm{X}_{2}(\mathrm{M}=\mathrm{Zn}, \mathrm{Cd}$ and $\mathrm{X}=\mathrm{N}, \mathrm{P}, \mathrm{As})$ calculated with HSE06 are presented in Fig. 5. Clearly, HSE06 func- 


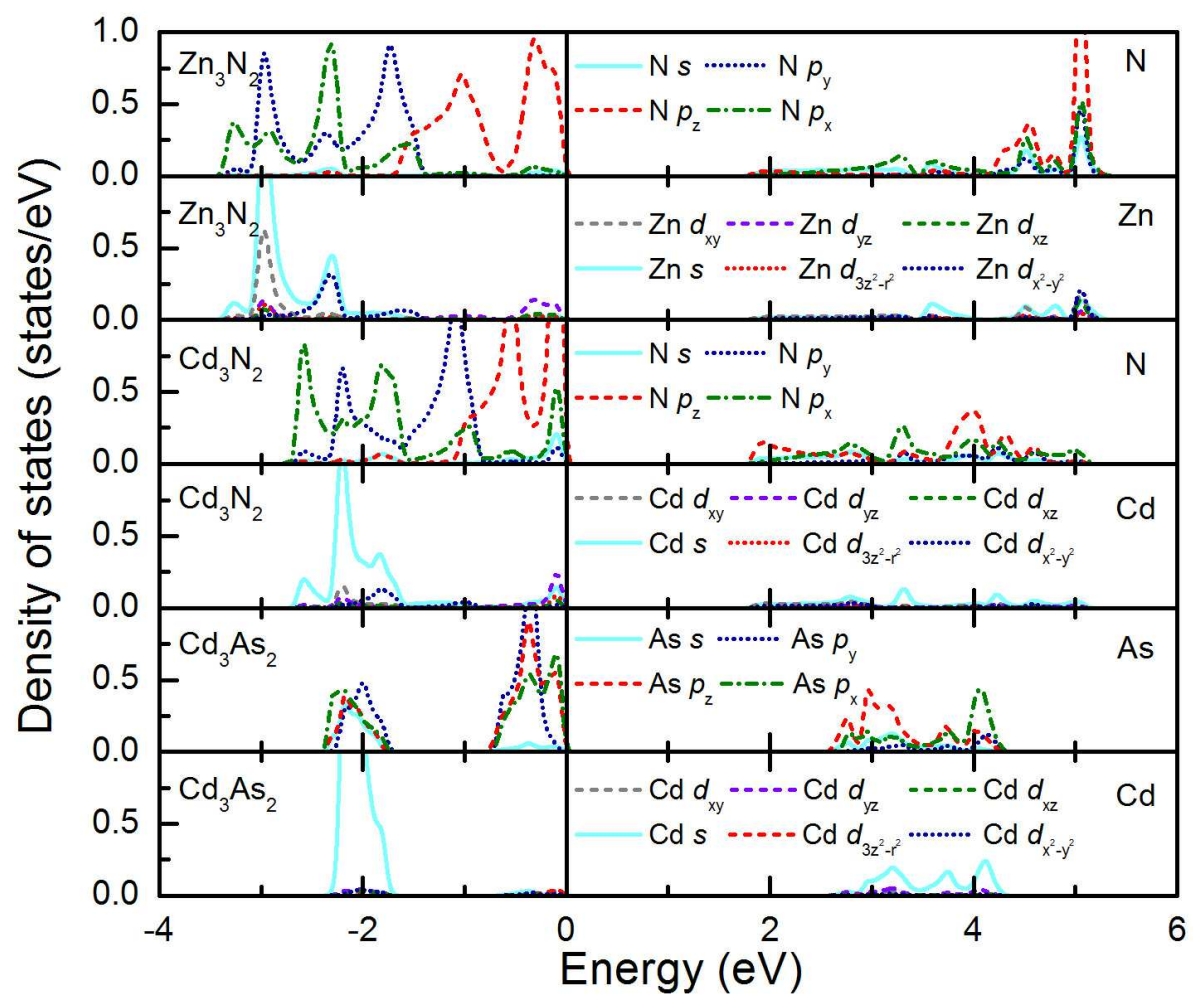

FIG. 4. (Color online) The partial DOS $\left(E_{F}=0 \mathrm{eV}\right.$, calculated with GGA, and projected in the atomic muffin tins) of the three 2D II-V semiconductor materials: $\mathrm{Zn}_{3} \mathrm{~N}_{2}, \mathrm{Cd}_{3} \mathrm{~N}_{2}$, and $\mathrm{Cd}_{3} \mathrm{As}_{2}$. It should be pointed out that the partial DOS of the interstitial region is not included here.

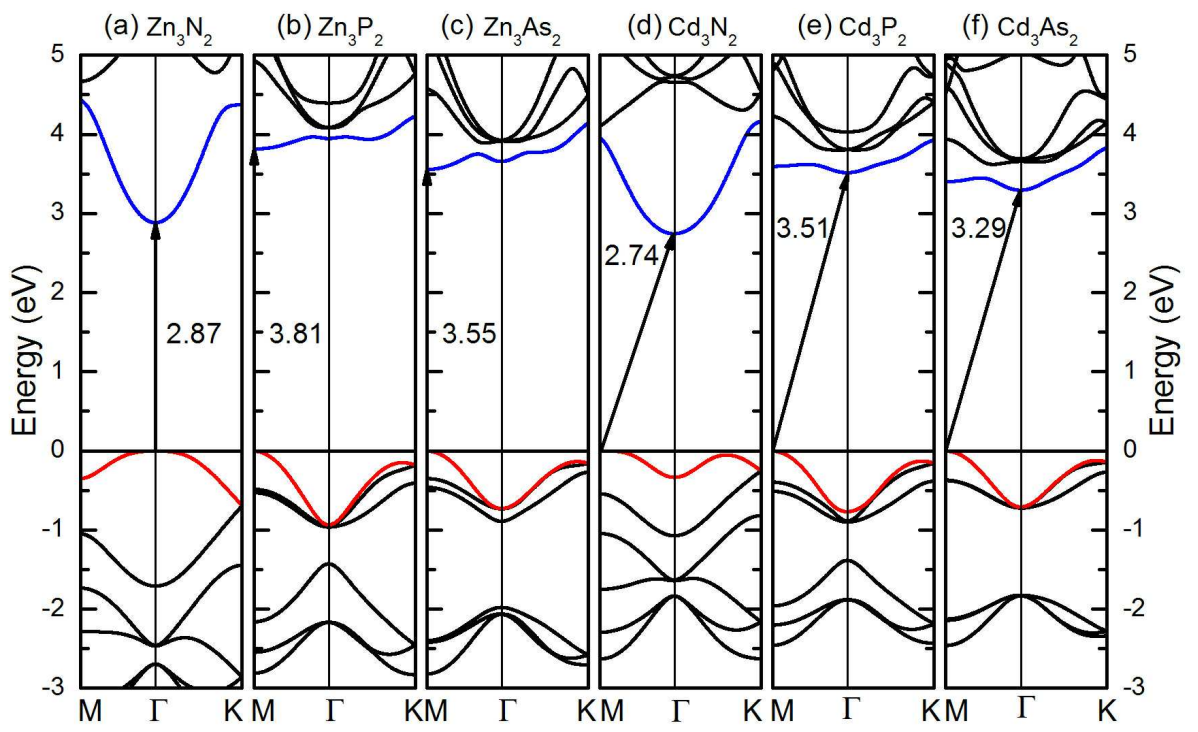

FIG. 5. (Color online) The band structures $\left(E_{F}=0 \mathrm{eV}\right)$ calculated with HSE06 functional ${ }^{22}$ of the six $2 \mathrm{D}$ materials of $\mathrm{M}_{3} \mathrm{X}_{2}$ $(\mathrm{M}=\mathrm{Zn}, \mathrm{Cd}$ and $\mathrm{X}=\mathrm{N}, \mathrm{P}, \mathrm{As})$, with the gaps being indicated.

tional leads to the wider band gaps of $2.87,3.81,3.55$, 2.74, 3.51 and $3.29 \mathrm{eV}$ than those with PBE for the 2D $\mathrm{Zn}_{3} \mathrm{~N}_{2}, \mathrm{Zn}_{3} \mathrm{P}_{2}, \mathrm{Zn}_{3} \mathrm{As}_{2}, \mathrm{Cd}_{3} \mathrm{~N}_{2}, \mathrm{Cd}_{3} \mathrm{P}_{2}$, and $\mathrm{Cd}_{3} \mathrm{As}_{2}$, respectively. These band gaps are wider than those of successfully fabricated $\mathrm{MoS}_{2}$ and recently theoretically stud- ied As monolayer ${ }^{13.36}$

Using HSE06 hybrid functional, we have also calculated effective carrier masses $m^{*}$ of the $2 \mathrm{D} \mathrm{M}_{3} \mathrm{X}_{2}$ $(\mathrm{M}=\mathrm{Zn}, \mathrm{Cd}$ and $\mathrm{X}=\mathrm{N}, \mathrm{P}, \mathrm{As})$ at $\mathrm{VBM}$ and $\mathrm{CBM}$. The calculated results are summarized in Table II. For 
the $2 \mathrm{D} \mathrm{Zn}_{3} \mathrm{~N}_{2}$, the calculated hole effective masses $m_{\Gamma \mathrm{K}}^{*}$ and $m_{\Gamma \mathrm{M}}^{*}$ are $0.24 m_{0}$ and $0.26 m_{0} \quad\left(m_{0}\right.$ is the mass of free-electron), which are close to those of arsenene $\left(m_{\Gamma \mathrm{K}}^{*}=0.23 m_{0}, m_{\Gamma \mathrm{M}}^{*}=0.29 m_{0}\right)$ and antimonene ( $\left.m_{\Gamma \mathrm{K}}^{*}=0.20 m_{0}, m_{\Gamma \mathrm{M}}^{*}=0.24 m_{0}\right)^{13}$ and smaller than those of monolayer $\mathrm{MoS}_{2}\left(m^{*}=0.48 m_{0}\right)^{37}$. For the $2 \mathrm{D} \mathrm{Cd} \mathrm{Cd}_{2}$, the calculated hole effective mass $m_{\mathrm{M} \Gamma}^{*}$ is $0.37 m_{0}$. However, For the $2 \mathrm{D} \mathrm{Zn}_{3} \mathrm{P}_{2}, \mathrm{Zn}_{3} \mathrm{As}_{2}, \mathrm{Cd}_{3} \mathrm{P}_{2}$ and $\mathrm{Cd}_{3} \mathrm{As}_{2}$, the hole effective masses $m_{\mathrm{M} \Gamma}^{*}$ are $0.04 m_{0}, 0.04 m_{0}, 0.03 m_{0}$ and $0.03 m_{0}$, maybe being able to cause high carrier mobilities. For the $\mathrm{Zn}_{3} \mathrm{~N}_{2}$ and $\mathrm{Cd}_{3} \mathrm{~N}_{2}$, the calculated electron effective masses, $0.03 m_{0}$, are much smaller than the hole effective masses, but for the $2 \mathrm{D} \mathrm{Zn}_{3} \mathrm{P}_{2}$ and $\mathrm{Zn}_{3} \mathrm{As}_{2}$, the electron effective masses, 0.17 and $0.10 m_{0}$, are substantially larger than the hole effective mass values. As for $2 \mathrm{D} \mathrm{Cd}_{3} \mathrm{P}_{2}$ and $\mathrm{Cd}_{3} \mathrm{As}_{2}$, the calculated electron effective masses, 0.05 and $0.04 m_{0}$, are only slightly larger than the hole effective masses.

TABLE II. Semiconductor gaps $(\mathrm{eV})$ and effective carrier mass values calculated with HSE06 ${ }^{22}$ of the six $2 \mathrm{D} \mathrm{M}_{3} \mathrm{X}_{2}$ $(\mathrm{M}=\mathrm{Zn}, \mathrm{Cd}$ and $\mathrm{X}=\mathrm{N}, \mathrm{P}, \mathrm{As})$. The band gap values in parentheses are calculated with PBE.

\begin{tabular}{cccc}
\hline \hline System & Gap & Hole mass & Electron mass \\
\hline $\mathrm{Zn}_{3} \mathrm{~N}_{2}$ & $2.87(1.83)$ & $0.24 m_{0}(\Gamma \mathrm{K}), 0.26 m_{0}(\Gamma \mathrm{M})$ & $0.03 m_{0}$ \\
$\mathrm{Zn}_{3} \mathrm{P}_{2}$ & $3.81(3.00)$ & $0.04 m_{0}(\mathrm{M} \Gamma)$ & $0.17 m_{0}(\mathrm{M} \Gamma)$ \\
$\mathrm{Zn}_{3} \mathrm{As}_{2}$ & $3.55(2.84)$ & $0.04 m_{0}(\mathrm{M} \Gamma)$ & $0.10 m_{0}(\mathrm{M} \Gamma)$ \\
$\mathrm{Cd}_{3} \mathrm{~N}_{2}$ & $2.74(1.83)$ & $0.37 m_{0}(\mathrm{M} \Gamma)$ & $0.03 m_{0}$ \\
$\mathrm{Cd}_{3} \mathrm{P}_{2}$ & $3.51(2.80)$ & $0.03 m_{0}(\mathrm{M} \Gamma)$ & $0.05 m_{0}$ \\
$\mathrm{Cd}_{3} \mathrm{As}_{2}$ & $3.29(2.61)$ & $0.03 m_{0}(\mathrm{M} \Gamma)$ & $0.04 m_{0}$ \\
\hline \hline
\end{tabular}

\section{Further Discussion}

The cation ( $\mathrm{Zn}$ or $\mathrm{Cd}$ ) has a nominal valence of $2+$ and the anion (N, P, or As) a nominal valence of 3-. Actually, the bond is not purely ionic and part of it is covalent, which can be shown by the nonzero weight of the filled $\mathrm{Zn}$ (or $\mathrm{Cd}$ ) s state in Fig. 4. Consequently, the valence bands in Fig. 3 are originated mainly from the $\mathrm{p}$ states of the anion and the conduction bands mainly from the $\mathrm{s}$ states of the cation. This can be seen through comparing Fig. 3 and Fig. 4 that the partial DOSs (projected in the atomic muffin tins) of the conduction bands are substantially smaller than those of the valence bands, and therefore the wave functions of the conduction bands are mainly in the interstitial region, being more extended in the real space. The incomplete transferring of the cation s electrons in the 2D II-V semiconductors is partly because the cation has only two coordinates and partly because the bond includes some covalence as it does in usual II-VI semiconductors.

At this stage, however, one may ask such a question: Can the 2D II-V semiconductors including twocoordinate cations (Zinc or Cadmium) be experimentally realized? On the theoretical side, we have shown through DFT calculated phonon spectra and total energy comparison with existing $3 \mathrm{D}$ materials that these $2 \mathrm{D}$ II-V semiconductor materials are structurally stable and should be experimentally realizable, although the cation has only two coordinates. On the experimental side, it has been already shown that one Zinc (and other transition metal) atom can indeed have two coordinates in various organic materials including Zinc (and other transition metals 17,18 . Therefore, the answer is certain.

The semiconductor gaps in these $2 \mathrm{D}$ semiconductors are between that of h-BN and those of $\mathrm{MoS}_{2}$, black $\mathrm{P}$, and As monolayer ${ }^{10}-13$. The effective hole masses of the $2 \mathrm{D} \mathrm{Zn}_{3} \mathrm{~N}_{2}$ and $\mathrm{Cd}_{3} \mathrm{~N}_{2}$ are slightly less than those of $2 \mathrm{D}$ $\mathrm{MoS}_{2}$, antimonene, and arsenene, but most of the effective carrier (either hole or electron) masses range from 0.03 to $0.05 m_{0}{ }^{13,18}$ Their $2 \mathrm{D}$ dilated honeycomb structure makes them be structurally compatible with most of the promising $2 \mathrm{D}$ materials, and thus they can be used to form hybrid structures with other $2 \mathrm{D}$ materials in order to design novel electronic, spintronic, optoelectronic, and other devices ${ }^{3}-\underline{\underline{n}}$.

\section{CONCLUSION}

In summary, we have predicted the six two-dimensional (2D) wide-band-gap II-V semiconductor materials $\mathrm{M}_{3} \mathrm{X}_{2}$ $(\mathrm{M}=\mathrm{Zn}, \mathrm{Cd}$ and $\mathrm{X}=\mathrm{N}, \mathrm{P}, \mathrm{As})$ with a dilated, buckled graphene-like honeycomb structure. The structural stability and feasibility of experimental realization of these 2D materials has been shown through DFT phonon spectra and total energy comparison with related existing 3D materials. They are also supported by the fact that there have already been many similar two-coordinate structures of $\mathrm{Zn}$ and other metallic atoms in various organic materials 17,18 . Our DFT study has shown that the $\mathrm{Zn}_{3} \mathrm{~N}_{2}, \mathrm{Zn}_{3} \mathrm{P}_{2}$, and $\mathrm{Zn}_{3} \mathrm{As}_{2}$ are direct band gap semiconductors with band gaps of 2.87, 3.81, and $3.55 \mathrm{eV}$, and however, the $\mathrm{Cd}_{3} \mathrm{~N}_{2}, \mathrm{Cd}_{3} \mathrm{P}_{2}$, and $\mathrm{Cd}_{3} \mathrm{As}_{2}$ are indirect band gap semiconductors with band gaps of 2.74, 3.51, and $3.29 \mathrm{eV}$, respectively. The dilated, buckled honeycomb structure enriches the family of two-dimensional materials. Our further DFT calculations show that the effective hole masses of the $2 \mathrm{D} \mathrm{Zn}_{3} \mathrm{~N}_{2}$ and $\mathrm{Cd}_{3} \mathrm{~N}_{2}$ are slightly less than that of well-known $2 \mathrm{D} \mathrm{MoS}_{2}$, and each of the six 2D materials has effective carrier (either hole or electron) masses down to 0.03 to $0.05 m_{0}$, having potential to achieve high carrier mobility. Therefore, these 2D II-V semiconductors may have promising applications in future electronic and optoelectronic devices.

\section{ACKNOWLEDGMENTS}

This work is supported by the Nature Science Foundation of China (Grant No. 11174359 and No. 11574366), by the Department of Science and Technology of China (Grant No. 2016YFA0300701 and No. 2012CB932302), 
* bgliu@iphy.ac.cn

1 K. S. Novoselov, A. K. Geim, S. V. Morozov, D. Jiang, M. I. Katsnelson, I. V. Grigorieva, S. V. Dubonos, and A. A. Firsov, Nature 438, 197 (2005).

2 S. Das Sarma, S. Adam, E. H. Hwang, and E. Rossi, Rev. Mod. Phys. 83, 407 (2011).

3 M. Khazaei, M. Arai, T. Sasaki, C.-Y. Chung, N. S. Venkataramanan, M. Estili, Y. Sakka, and Y. Kawazoe, Adv. Funct. Mater. 23, 2185 (2013).

4 A. B. Kaul, J. Mater. Res. 29, 348 (2014).

5 A. C. Ferrari, F. Bonaccorso, and V. Falko, Nanoscale 7, 4598 (2015).

${ }^{6}$ S. Roche, J. Akerman, B. Beschoten, J.-C. Charlier, M. Chshiev, S. P. Dash, B. Dlubak, J. Fabian, A. Fert, M. Guimaraes, F. Guinea, I. Grigorieva, C. Schonenberger, P. Seneor, C. Stampfer, S. O. Valenzuela, X. Waintal, and B. van Wees, 2D Mater. 2, 030202 (2015).

7 V. Meunier, A. G. Souza Filho, E. B. Barros, and M. S. Dresselhaus, Rev. Mod. Phys. 88, 025005 (2016).

8 G. R. Bhimanapati, Z. Lin, V. Meunier, Y. Jung, J. Cha, S. Das, D. Xiao, Y. Son, M. S. Strano, V. R. Cooper, L. Liang, S. G. Louie, E. Ringe, W. Zhou, S. S. Kim, R. R. Naik, B. G. Sumpter, H. Terrones, F. Xia, Y. Wang, J. Zhu, D. Akinwande, N. Alem, J. A. Schuller, R. E. Schaak, M. Terrones, and J. A. Robinson, ACS Nano 9, 11509 (2015).

9 C. Grazianetti, E. Cinquanta, and A. Molle, 2D Mater. 3, 012001 (2016).

10 X. Blase, A. Rubio, S. G. Louie, and M. L. Cohen, Europhys. Lett. 28, 335 (1994).

11 K. F. Mak, L. Changgu, J. Hone, J. Shan, and T. F. Heinz, Phys. Rev. Lett. 105, 136805 (2010).

12 J. S. Qiao, X. H. Kong, Z. X. Hu, F. Yang, and W. Ji, Nat. Commun. 5, 4475 (2014).

13 S. L. Zhang, Y. Zhang, Y. F. Li, Z. F. Chen, and H. B. Zeng, Angew. Chem. 127, 3155 (2015).

14 B. Radisavljevic, A. Radenovic, J. Brivio, V. Giacometti, and A. Kis, Nat. Nanotechnol. 6, 147 (2011).

15 H. Liu, A. T. Neal, Z. Zhu, Z. Luo, X. Xu, D. Tomanek, and P. D. Ye, ACS Nano 8, 4033 (2014).
${ }^{16}$ F. Xia, H. Wang, and Y. Jia, Nat. Commun. 5, 4458 (2014).

17 T. Nguyen, A. Panda, M. M. Olmstead, A. F. Richards, M. Stender, M. Brynda, and P. P. Power, J. Am. Chem. Soc. 127, 8545 (2005).

18 J. Hicks, E. J. Underhill, C. E. Kefalidis, L. Maron, and C. Jones, Angew. Chem. Int. Ed. 54, 10000 (2015).

19 G. Kresse and D. Joubert, Phys. Rev. B 59, 1758 (1999).

20 P. E. Blochl, Phys. Rev. B 50, 17953 (1994).

21 J. P. Perdew, K. Burke, and M. Ernzerhof, Phys. Rev. Lett. 77, 3865 (1996).

22 J. Heyd, G. E. Scuseria, and M. Ernzerhof, J. Chem. Phys. 118, 8207 (2003).

23 S. Baroni, S. De Gironcoli, A. Dao Corso, and P. Giannozzi, Rev. Mod. Phys. 73, 515 (2013).

24 A. Togo, F. Oba, and I. Tanaka, Phys. Rev. B 78, 134106 (2008).

25 Y. F. Li, Y. L. Liao, and Z. F. Chen, Angew. Chem. Int. Ed. 53, 7248 (2014).

26 D. E. Partin, D. J. Williams, and M. O. Keeffe, J. Solid Stat. Chem. 132, 56 (1997).

27 M. Futsuhara, K. Yoshioka, and O. Takai, Thin Solid Films 322, 274 (1998).

28 F. Karau and W. Schnick, Z. Anorg. Allg. Chem. 633, 223 (2007).

29 I. E. Zanin, K. B. Aleinikova, M. M. Afanasiev, and M. Y. Antipin, J. Struct. Chem. 45, 844 (2004).

30 I. E. Zanin, K. B. Aleinikova, M. M. Afanasiev, and M. Y. Antipin, J. Struct. Chem. 47, 78 (2006).

31 D. R. Rao and A. Nayak, J. Mater. Sci. 27, 4389 (1992).

32 P. J. Lin-Chung, Phys. Stat. Sol. B 47, 33 (1971).

33 V. Y. Shevchenko, S. F. Marenkin, and V. F. Ponomarev, Inorg. Mater. 13, 1527 (1977).

34 A. Pietraszko and K. Lukaszewicz, Acta Crystallographica 25, 988 (1969).

35 L. Passerini, Gazzetta Chimica Italiana 58, 655 (1928).

${ }^{36}$ Y. H. Lee, X. Q. Zhang, W. J. Zhang, M. T. Chang, C. T. Lin, K. D. Chang, Y. C. Yu, J. T. W. Wang, C. S. Chang, L. J. Li, and T. W. Lin, Adv. Mater. 24, 2320 (2012).

37 H. Peelaers and C. G. Van de Walle, Phys. Rev. B 86, 241401 (2012). 